\title{
Hormone and Metabolite Profiles in Nesting Green and Flatback Turtles: Turtle Species with Different Life Histories
}

\author{
Maria P. Ikonomopoulou, ${ }^{1,2}$ Adrian J. Bradley, ${ }^{1}$ Kammarudin Ibrahim, ${ }^{3}$ Colin J. Limpus, \\ Manuel A. Fernandez-Rojo, ${ }^{5}$ Dimitrios Vagenas, ${ }^{6}$ and Joan M. Whittier ${ }^{1}$ \\ ${ }^{1}$ School of Biomedical Sciences, The University of Queensland, Brisbane, QLD 4072, Australia \\ ${ }^{2}$ Institute for Molecular Bioscience, Level 2 North, The University of Queensland, Services Road, Building 80, \\ St Lucia Campus, St Lucia, QLD 4072, Australia \\ ${ }^{3}$ Department of Marine Parks Malaysia, No. 25 Persiaran Perdana, Presint 4, 62574 Putrajaya, Malaysia \\ ${ }^{4}$ Queensland Department of Environment and Heritage Protection, Australia \\ ${ }^{5}$ Hepatic Fibrosis Group, Queensland Institute of Medical Research, 300 Herston Road, QLD 4006, Australia \\ ${ }^{6}$ Institute of Health and Biomedical Innovation, Queensland University of Technology, 60 Musk Avenue, \\ Kelvin Grove, QLD 4059, Australia
}

Correspondence should be addressed to Maria P. Ikonomopoulou; m.ikonomopoulou@uq.edu.au

Received 16 April 2014; Revised 5 August 2014; Accepted 17 August 2014; Published 27August 2014

Academic Editor: Raine Kortet

Copyright (c) 2014 Maria P. Ikonomopoulou et al. This is an open access article distributed under the Creative Commons Attribution License, which permits unrestricted use, distribution, and reproduction in any medium, provided the original work is properly cited.

\begin{abstract}
Herbivorous turtle, Chelonia mydas, inhabiting the south China Sea and breeding in Peninsular Malaysia, and Natator depressus, a carnivorous turtle inhabiting the Great Barrier Reef and breeding at Curtis Island in Queensland, Australia, differ both in diet and life history. Analysis of plasma metabolites levels and six sex steroid hormones during the peak of their nesting season in both species showed hormonal and metabolite variations. When compared with results from other studies progesterone levels were the highest whereas dihydrotestosterone was the plasma steroid hormone present at the lowest concentration in both $C$. mydas and $N$. depressus plasma. Interestingly, oestrone was observed at relatively high concentrations in comparison to oestradiol levels recorded in previous studies suggesting that it plays a significant role in nesting turtles. Also, hormonal correlations between the studied species indicate unique physiological interactions during nesting. Pearson correlation analysis showed that in N. depressus the time of oviposition was associated with elevations in both plasma corticosterone and oestrone levels. Therefore, we conclude that corticosterone and oestrone may influence nesting behaviour and physiology in N. depressus. To summarise, these two nesting turtle species can be distinguished based on the hormonal profile of oestrone, progesterone, and testosterone using discriminant analysis.
\end{abstract}

\section{Introduction}

Hormones have various functions across animal taxa. In birds, for example, testosterone is linked to mating success, while corticosterone has been shown to support energetically demanding processes [1]. In vertebrates glucocorticoid hormones can assist in the modulation of life-history events, survival probabilities, and fecundity [2]. Similarly steroid hormones play an essential role in the reproductive behaviour and sexual development in marine turtles [3]. Sex determination in sea turtles is regulated by incubation temperatures and by exogenous steroid hormones $[4,5]$. In addition to determining sex, steroids have also been causally related to various physiological and behavioural actions in sea turtles. For example, corticosterone and testosterone have been associated with hepatic regulation and ovarian function during nesting activities in Caretta caretta [68]. Corticosterone concentration decreases when a turtle is subjected to stress or drops to low levels when a female turtle is breeding [9-11]. Nesting Lepidochelys olivacea during arribadas (mass nesting behaviour) maintain low corticosterone level as a mechanism of controlling stress [12]. However, a low 
adrenocortical response may assist reproduction in sea turtles $[7,8]$. Fatty acids and glucose, derived from fat and glycogen, respectively, are characterised as indicators of the required energy for nesting $[7,8,13]$. In Chelonia mydas corticosterone increases glycerol release from adipose tissue suggesting that this hormone induces the mobilization of triglycerides accumulated in the adipocytes [14]. Consequently, it causes the release of free fatty acid into the blood during nesting [7, $8]$. Because sea turtles are largely aphagic during reproductive and nesting activities $[15,16]$, corticosterone induces free fatty acids release from adipose tissue to compensate for the lack of food and the energy demands during courtship and nesting activities in sea turtles, indicating that corticosterone is an essential steroid hormone for energetic homeostasis of sea turtles during reproduction [13].

Thyroxine is another hormone responsible for regulating energy availability in animals. High plasma thyroxine concentrations increase the metabolic rate in animal tissues [17], reflecting thyroxine levels as indicators of metabolic activity. In the rainbow trout, Salmo gairdneri, thyroid activity increases thyroxine secretion, which affects body metabolism and it is associated with yolk deposition, mating, or ovulation [18].

Taking into consideration the important roles of steroids and metabolites (i.e., glucose and triglycerides) during the reproductive cycles, we hypothesised that despite similarities during nesting, the steroid hormone and metabolite profiles in sea turtles is specific for each population and species. Hence, two turtle species (C. mydas versus Natator depressus) with different diet (herbivorous versus carnivorous) and distribution (Peninsular, Malaysia, versus Queensland, Australia) were likely to have unique hormone and metabolite profiles. We studied also the role of oestrone in nesting $C$. mydas and $N$. depressus and measured the plasma concentration profile of thyroxine, a hormone that has not been investigated before in nesting turtles. Blood metabolites (i.e., glucose and triglycerides) in conjunction with steroid hormones assist turtles to conserve energy during breeding and nesting season (e.g., C. mydas $[7,8])$. Hence, understanding metabolites role and their interactions with hormones during nesting activities in sea turtles will provide a more comprehensive knowledge on sea turtle biology. Consequently, we also examined the interactions among hormone and metabolite levels in both species as well as the influence of nesting history, time of oviposition, and size (curved carapace length measurements) to hormone and metabolite levels in $N$. depressus. Similarly, we studied a potential link between egg size (egg dimensions) and hormone and/or metabolite levels in $N$. depressus. Last but not least, we used discriminant analysis to separate the two species based on their hormones and metabolite levels. We argued that this method would provide an additional insight on the nesting biology of the studied species.

\section{Materials and Methods}

2.1. Field Sites. This study investigated hormonal and metabolite patterns collected at the peak of the respective nesting seasons for C. mydas (Ibrahim, personal observations) and $N$. depressus $[19,20]$. Chelonia mydas sampling was conducted between June and September 2004 at Ma’Daerah beach $\left(4^{\circ} 34^{\prime} 15.50^{\prime} \mathrm{N}, 103^{\circ} 27^{\prime} 51.93^{\prime} \mathrm{E}\right)$, Kuala Terengganu State, in Peninsular Malaysia. Natator depressus sampling was conducted between November and December 2006 at Curtis Island $\left(23^{\circ} 45^{\prime} \mathrm{S}, 151^{\circ} 17^{\prime} \mathrm{E}\right)$, Gladstone, in central Queensland, Australia.

2.2. Blood Collection. Blood samples $(2 \mathrm{~mL})$ were collected from the dorsal cervical sinus from 14 nesting C. mydas and 20 nesting $N$. depressus using a $21 \mathrm{G}$ needle and a $5 \mathrm{~mL}$ syringe immediately after oviposition as previously been described [21]. Blood samples were initially stored in heparinized tubes on ice $(<2 \mathrm{hr})$ prior to being centrifuged at $6,000 \mathrm{rpm}$ for 10 minutes. For C. mydas in Peninsular Malaysia, plasma was decanted and frozen in liquid nitrogen and then transferred on dry ice to Queensland and stored at $-25^{\circ} \mathrm{C}$ until analysed. The $N$. depressus plasma samples were kept for $<2 \mathrm{hr}$ on ice and then stored at $-25^{\circ} \mathrm{C}$ until analysed.

2.3. Biometric Measurements in Natator depressus. Midline curved carapace length (CCL) was measured with a flexible tape by two independent turtle researchers (the author MI always conducted one of the measurements) as previously been described [22]. Egg size was mean product of the maximum and minimum egg diameter of three eggs from each nesting turtle. Time of oviposition (TO) was recorded as a continuous variable from 16:00 to 24:00. Nesting history was acquired from the Queensland Turtle Research Project database. The year each individual turtle was reported nesting for the first time was grouped in three categories: first time nesting turtles in 2006; younger remigrant turtles, which began breeding during 1998-2002; and older remigrant turtles, which began breeding during 1993-1997.

2.4. Steroid Hormone Analysis. Plasma samples from C. mydas and $N$. depressus were analysed directly using specific enzyme linked immunoassays (ELISAs) for testosterone $(\mathrm{T})$, dihydrotestosterone (DHT), progesterone $(\mathrm{P})$, thyroxine $\left(\mathrm{T}_{4}\right)$, oestrone $\left(\mathrm{E}_{1}\right)$ (dbc Diagnostics, Canada), and corticosterone (B) (Abacus Diagnostics, Australia). Oestrone and B ELISA assays have been validated previously for use in marine turtle and crocodilian samples, respectively [23, 24]. Still, in this study, all ELISA assays were validated by using pooled samples from nesting $C$. mydas $(n=4)$ and $N$. depressus $(n=2-4)$ over a total period of four months and with estimates comparable to those provided in the kits by the manufacturers. Pooled samples in duplicates were used for intra-assay, inter-assay variation, and minimum assay sensitivity (Table 1). For $\mathrm{E}_{1}, \mathrm{~T}, \mathrm{DHT}, \mathrm{T}_{4}, \mathrm{P}$, and B ELISA kits the published intra-assay precision values, based upon three human serum samples (except B, which was based upon two human serum samples) were assayed ten times (Table 1). Inter-assay variations of $\mathrm{T}_{4}, \mathrm{P}$, and DHT ELISA kits were not possible because only one kit of these steroids was used. However, because no major intra-assay variations were observed in these ELISA kits there was a confidence of the 
TABLE 1: Inter-assay, intra-assay, and sensitivity of specific enzyme linked immunoassay (ELISA) kits for thyroxine ( $\left.\mathrm{T}_{4}\right)$, corticosterone (B), progesterone $(\mathrm{P})$, testosterone $(\mathrm{T})$, oestrone $\left(\mathrm{E}_{1}\right)$, and dihydrotestosterone $(\mathrm{DHT})$ measurements in Chelonia mydas and Natator depressus and Homo sapiens. All samples were assayed ten times.

\begin{tabular}{|c|c|c|c|c|c|}
\hline Hormone assay & Species & $\begin{array}{c}\text { Mean (SD) } \\
\text { inter-assay } \\
\text { variation }\end{array}$ & $\begin{array}{c}\text { Mean (SD) } \\
\text { intra-assay } \\
\text { variation }\end{array}$ & Assay sensitivity & Reference \\
\hline \multirow{3}{*}{ Thyroxine } & Chelonia mydas & - & $2.25 \pm 0.79$ & \multirow{3}{*}{$0.6 \mu \mathrm{g} / 100 \mu \mathrm{L}$} & \multirow{3}{*}{ This study } \\
\hline & Natator depressus & - & $1.85 \pm 1.04$ & & \\
\hline & Homo sapiens & $7.5 \pm 0.86$ & $11.2 \pm 0.7$ & & \\
\hline \multirow{3}{*}{ Corticosterone } & Chelonia mydas & $13.17 \pm 6.64$ & $3.49 \pm 1.42$ & \multirow{3}{*}{$0.17 \mathrm{ng} / \mathrm{mL}$} & \multirow{2}{*}{ This study } \\
\hline & Natator depressus & $16.19 \pm 5.77$ & $3.34 \pm 0.25$ & & \\
\hline & Homo sapiens & $6.45 \pm 0.45$ & $8.6 \pm 0.35$ & & Abacus Diagnostics \\
\hline \multirow{3}{*}{ Progesterone } & Chelonia mydas & - & $5.72 \pm 3.79$ & \multirow{3}{*}{$0.1 \mathrm{ng} / \mathrm{mL}$} & \multirow{3}{*}{ This study } \\
\hline & Natator depressus & - & $4.41 \pm 1.39$ & & \\
\hline & Homo sapiens & $10.4 \pm 0.2$ & $11.4 \pm 1.2$ & & \\
\hline \multirow{3}{*}{ Testosterone } & Chelonia mydas & $4.52 \pm 2.40$ & $1.40 \pm 0.64$ & & \multirow{3}{*}{ This study } \\
\hline & Natator depressus & $11.8 \pm 4.08$ & $4.53 \pm 3.63$ & $0.022 \mathrm{ng} / \mathrm{mL}$ & \\
\hline & Homo sapiens & $7.97 \pm 0.88$ & $7.3 \pm 0.69$ & & \\
\hline \multirow{3}{*}{ Oestrone } & Chelonia mydas & $4.52 \pm 2.40$ & $1.40 \pm 0.65$ & & \multirow{3}{*}{ This study } \\
\hline & Natator depressus & $11.8 \pm 4.08$ & $4.53 \pm 3.65$ & $0.01 \mathrm{pg} / \mathrm{mL}$ & \\
\hline & Homo sapiens & $7.67 \pm 0.73$ & $9.5 \pm 1.4$ & & \\
\hline \multirow{3}{*}{ Dihydrotestosterone } & Chelonia mydas & - & $9.22 \pm 3.47$ & & \multirow{2}{*}{ This study } \\
\hline & Natator depressus & - & $4.49 \pm 1.38$ & $0.006 \mathrm{ng} / \mathrm{mL}$ & \\
\hline & Homo sapiens & $6.92 \pm 2.29$ & $8.5 \pm 1.86$ & & $\mathrm{dpc}$, Inc \\
\hline
\end{tabular}

Note: inter-assay variation was not determined in $\mathrm{P}, \mathrm{T}_{4}$, and DHT ELISA kits for either turtle species.

kit validation in marine turtle plasma. The percent coefficient of variation $(\% \mathrm{CV})$ was determined as equal to $\mathrm{SD} /$ mean * $100(\%)$.

2.5. Enzyme Linked Immunoassays. Detailed information on ELISA assays is provided in Ikonomopoulou [25]. In brief, all ELISA kits $\left(\mathrm{E}_{1}, \mathrm{~T}, \mathrm{DHT}, \mathrm{T}_{4}, \mathrm{P}\right.$, and $\left.\mathrm{B}\right)$ used an antisteroid antibody, a steroid-biotin conjugate solution, and a steroid-avidin-horse radish peroxide conjugate. Appropriate calibration standards, positive control, and plasma samples were added to the plate and incubated for 1-2 hrs, depending on the steroid and the manufacturer's protocol. After the incubation period, the plate was washed and incubated with $\operatorname{TMB}\left(3,3^{\prime}, 5,5^{\prime}\right.$-tetramethylbenzidine) for $\sim 15$ minutes on a Benchmark Microwell Plate Reader. The steroid concentrations $\left(\mathrm{E}_{1}, \mathrm{~T}, \mathrm{DHT}, \mathrm{T}_{4}, \mathrm{P}\right.$, and $\left.\mathrm{B}\right)$ of the unknown samples were interpolated (using an Excel program for PC) based on the steroid calibrations curves.

All samples were within the range of the calibration curves enabling the steroid protocols given by the manufacturers to be employed without modifications (e.g., sample dilutions). The ELISA kits were tested for precision, sensitivity, accuracy, and steroid specificity.

2.6. Precision (CV\%). Calibration curves for each steroid ELISA kit for C. mydas and N. depressus were completed by measuring the absorbance of six calibrators as described in Ikonomopoulou [25]. Two calibrators (for each measured steroid) were run as unknown samples to test intra-assay variation, determining accuracy in each ELISA kit.

2.7. Sensitivity. The sensitivity of the ELISA kits was determined by measuring the mean absorbance (OD) of the lowest standard concentrations as described in Ikonomopoulou [25] and comparing this with the absorbance of samples containing no hormone. The sensitivity was reported to be $\mathrm{E}_{1}: 10.0 \mathrm{pg} / \mathrm{mL} ; \mathrm{T}: 0.022 \mathrm{ng} / \mathrm{mL}$; (dbc, Inc.); DHT: $6.0 \mathrm{pg} / \mathrm{mL}$; $\mathrm{T}_{4}: 0.6 \mu \mathrm{g} / 100 \mu \mathrm{L} ; \mathrm{P}: 0.1 \mathrm{ng} / \mathrm{mL} ;$ and B: $0.17 \mathrm{ng} / \mathrm{mL}$.

2.8. Accuracy. ELISA accuracy for marine turtles (C. mydas and $N$. depressus) was determined using a positive control sample containing the appropriate steroid $\left(\mathrm{E}_{1}, \mathrm{~T}, \mathrm{DHT}, \mathrm{P}\right.$, $\mathrm{B}$, and $\mathrm{T}_{4}$ ) in human serum. The expected concentration of the control was divided by the measured concentration and multiplied by 100 to obtain a percentage. The determined accuracy in each ELISA kit for marine turtles was as follows: $\mathrm{E}_{1}$ (89.3\%); T (95.2\%); DHT (90.70\%); $\mathrm{T}_{4}$ (100.61\%); P (94.72\%); and B (100.85\%). All the \% accuracy values for the steroids were within the manufacturers reported levels $\mathrm{E}_{1}$ (88-125\%); T (80.5-110.1\%); DHT (88-97.9\%); $\mathrm{T}_{4}$ (93.9$116.4 \%) ; \mathrm{P}(78-124 \%)$; and B (94-116\%).

2.9. Specificity (\% CV). The ELISA kits were highly specific to the steroids they measured. All the ELISA kits (T, E1, P, $\mathrm{T}_{4}$, and DHT) were tested for specificity in the commercial laboratory (unpublished data, dpc, Inc) and B ELISA kit were 
TABLE 2: Quality control analysis for glucose and triglyceride in nesting Chelonia mydas and Natator depressus.

\begin{tabular}{lccc}
\hline Metabolite & Mean value (mmol/L) & SD & $\% \mathrm{CV}$ \\
\hline Triglyceride (sample 1) & 1.75 & 0.098 & 4.1 \\
Triglyceride (sample 2) & 3.56 & 0.122 & 3.43 \\
Glucose (sample 1) & 5.5 & 0.392 & 2.72 \\
Glucose (sample 2) & 13.6 & 0.342 & 2.74 \\
\hline
\end{tabular}

tested in the laboratories of Abacus Diagnostics (unpublished data, Abacus Diagnostics). Information on all steroid ELISA kits that crossed reactivity with other steroids is given in Ikonomopoulou [25].

2.10. Metabolite Analysis. Glucose and triglyceride in the plasma of nesting C. mydas and $N$. depressus females were measured using an automated Olympus AU400 analyser and Olympus reagents (Olympus Diagnostica, Clare Island) by The University of Queensland, Department of Veterinary Pathology, Unit Diagnostic Service. Glucose and triglyceride assays have been previously validated for marine turtles by the Department of Veterinary Pathology Unit (Table 2). Glucose analysis was performed according to HKG6P-DH normal application with NIST SRM 965 traceability (Veterinary Pathology Unit, internal methods). The triglyceride analysis was done according to GPO-POD normal application with Isotope dilution mass spectrometry reference method traceability (Veterinary Pathology Unit, internal methods).

2.11. Hormone and Metabolites Statistical Analysis. All values are reported as mean hormone and metabolite levels $(\mathrm{ng} / \mathrm{mL})$ \pm standard error (SE). R statistical programming language was used for the analysis [26]. All traits were analysed using a one way ANOVA, using "lm" function of the "stats" package [26], with the metabolite/hormone level as the outcome variable and turtle species as the explanatory variables. Residual analysis was performed to assess potential violations of the assumptions of ANOVA. No such violations were detected (results not shown). As an extra safeguard, and for assessing the robustness of such estimates, a bootstrap procedure was used. This procedure gave similar results to the simple ANOVA and thus only the ANOVA results are presented. Least square means were estimated using the Ismeans $\mathrm{R}$ package [27] and are presented here. DHT was not included in the statistical analysis since the values were found to be below the assays sensitivity level. In addition, we explored the associations between metabolites and hormones in the two species. We performed Pearson's correlation analysis, using "Hmisc" package [28], within each species testing two different hypothesis. (i) Are the correlations in each species in our sample different from zero? (ii) Are the two sets of correlations different from each other (i.e., between species comparison)?

We also assessed whether a combination of the above hormones and metabolites could be used to differentiate the two species. This analysis would answer a question such as the following. "Given a blood sample from a turtle of these
TABLE 3: Least squares means, standard errors, and significance for hormones and metabolites between Natator depressus $(N=20)$ and Chelonia mydas $(N=14)$ turtles.

\begin{tabular}{lccccc}
\hline & $\begin{array}{c}\text { Natator } \\
\text { depressus }\end{array}$ & s.e. & $\begin{array}{c}\text { Chelonia } \\
\text { Mydas }\end{array}$ & s.e. & $P$ \\
\hline Progesterone & 24.03 & 2.31 & 34.04 & 2.76 & 0.01 \\
Testosterone & 0.80 & 0.05 & 0.63 & 0.06 & 0.05 \\
Corticosterone & 0.41 & 0.05 & 0.19 & 0.06 & 0.01 \\
Oestrone & 1.54 & 0.05 & 0.47 & 0.06 & 0.00 \\
DHT & 2.40 & 0.07 & 2.20 & 0.08 & 0.08 \\
Thyroxine & 0.39 & 0.02 & 0.37 & 0.03 & 0.64 \\
Triglycerides & 5.39 & 0.35 & 4.42 & 0.42 & 0.09 \\
Glucose & 4.46 & 0.17 & 4.06 & 0.20 & 0.15 \\
\hline
\end{tabular}

species, could we use a combination of hormones/metabolites to identify from which species the sample came?" This question was approached using linear discriminant analysis, in R using the MASS package [29].

2.12. The Association of Hormones and Metabolites with Natator depressus Biometric Measurements. Data on nesting history, turtle size (CCL), egg size, and the time of oviposition were also collected. These biometric measurements could be associated with the hormone and metabolite profile of turtles and thus a Pearson correlation analysis was performed. It should be noted that the analysis of time was performed both on the original scale and with decimal time. The results were identical and thus only these for decimal time are presented. It should be noted that in the statistical analysis for the evaluation of nesting history on hormones/metabolites profile only two categories were used because there was only one turtle reported as first time nesting turtle in 2006.

\section{Results}

3.1. Species-Specific Steroid Hormonal Profile in Sea Turtles. Steroid hormonal profiling from plasma samples obtained from C. mydas and $N$. depressus while nesting showed that among all of the analysed steroid hormones the mean levels $( \pm \mathrm{SE})$ of $\mathrm{P}$ were the highest $(34.04 \pm 2.76$ versus $24.03 \pm$ $2.31 \mathrm{ng} / \mathrm{mL})$ in both turtle species. Progesterone was followed by $\mathrm{T}_{4}(3.7 \pm 0.03$ versus $3.9 \pm 0.02 \mathrm{ng} / \mathrm{mL}), \mathrm{T}(0.63 \pm 0.06$ versus $0.8 \pm 0.05 \mathrm{ng} / \mathrm{mL}), \mathrm{E}_{1}(0.47 \pm 0.06$ versus $1.54 \pm$ $0.05 \mathrm{ng} / \mathrm{mL})$, and $\mathrm{B}(0.13 \pm 0.02$ : below assay sensitivity versus $0.38 \pm 0.02 \mathrm{ng} / \mathrm{mL})$ and DHT values for both species were below assay sensitivity $(\sim 0.002 \pm 0.001)$. Hence, DHT data obtained from the statistical analysis should be interpreted with caution.

As it can be seen in Table 3, statistically significant differences were observed for all hormones except thyroxine (ANOVA: $\mathrm{F}_{1,32}=0.23$ ). Chelonia mydas had higher levels of progesterone but lower levels for all other hormones and metabolites.

The within species correlations are shown in Tables 4 and 5 . The correlation between progesterone and testosterone was significantly different from zero for both species 
TABLE 4: Pearson correlations and $P$ values (in brackets) of hormones for 14 nesting Chelonia mydas turtles.

\begin{tabular}{|c|c|c|c|c|c|c|c|c|}
\hline & Progesterone & Testosterone & Corticosterone & Oestrone & DHT & Thyroxine & Triglycerides & Glucose \\
\hline Progesterone & 1 & & & & & & & \\
\hline Testosterone & $0.80(0.00)$ & 1 & & & & & & \\
\hline Corticosterone & $0.27(0.36)$ & $0.16(0.58)$ & 1 & & & & & \\
\hline Estrone & $0.42(0.13)$ & $0.4(0.15)$ & $0.08(0.79)$ & 1 & & & & \\
\hline DHT & $-0.29(0.31)$ & $-0.38(0.18)$ & $-0.05(0.85)$ & $0.1(0.75)$ & 1 & & & \\
\hline Thyroxin & $-0.37(0.2)$ & $-0.19(0.50)$ & $-0.22(0.44)$ & $0.46(0.10)$ & $0(0.99)$ & 1 & & \\
\hline Triglycerides & $-0.02(0.94)$ & $0.1(0.74)$ & $-0.113(0.96)$ & $0.28(0.34)$ & $0.33(0.24)$ & $0.1(0.74)$ & 1 & \\
\hline Glucose & $0.07(0.81)$ & $-0.38(0.18)$ & $0.14(0.64)$ & $0.02(0.93)$ & $0.35(0.22)$ & $-0.16(0.58)$ & $0.08(0.79)$ & 1 \\
\hline
\end{tabular}

TABLE 5: Pearson correlations and $P$ values (in brackets) of hormones for 20 Natator depressus turtles.

\begin{tabular}{|c|c|c|c|c|c|c|c|c|}
\hline & Progesterone & Testosterone & Corticosterone & Oestrone & DHT & Thyroxine & Triglycerides & Glucose \\
\hline Progesterone & 1 & & & & & & & \\
\hline Testosterone & $0.63(0.00)$ & 1 & & & & & & \\
\hline Corticosterone & $0.47(0.04)$ & $0.19(0.42)$ & 1 & & & & & \\
\hline Oestrone & $0.36(0.12)$ & $0.03(0.89)$ & $0.64(0.00)$ & 1 & & & & \\
\hline DHT & $0.04(0.87)$ & $-0.07(0.76)$ & $0.04(0.85)$ & $0.31(0.18)$ & 1 & & & \\
\hline Thyroxine & $0.26(0.27)$ & $0.51(0.02)$ & $0.13(0.59)$ & $-0.02(0.92)$ & $-0.17(0.49)$ & 1 & & \\
\hline Triglycerides & $0.27(0.25)$ & $-0.15(0.52)$ & $0.22(0.34)$ & $0.09(0.69)$ & $-0.2(0.39)$ & $-0.38(0.10)$ & 1 & \\
\hline Glucose & $-0.41(0.07)$ & $-0.06(0.81)$ & $-0.17(0.48)$ & $-0.01(0.98)$ & $0.11(0.66)$ & $-0.27(0.24)$ & $-0.13(0.59)$ & 1 \\
\hline
\end{tabular}

(Pearson correlation: 0.80 and 0.63 for C. mydas and $N$. depressus, resp.), whereas the correlations between corticosterone-progesterone, corticosterone-oestrone, and testosterone-thyroxine were statistically significant from zero for $N$. depressus (Pearson correlation: 0.47, 0.64, and 0.51, resp.). Interestingly the thyroxine-testosterone correlation closely approached statistical significance for difference between the two species (Pearson correlations of -0.19 and 0.51 , resp.) $(P=0.05$; Table 6).

The linear discriminant analysis using a stepwise procedure resulted in 3 variables being selected: oestrone, progesterone, and testosterone. The optimal function for discrimination was $\mathrm{D}=(-4.35 \times$ oestrone $)+(0.0975 \times$ progesterone $)-(2.915 \times$ testosterone $)$. This function was able to separate $100 \%$ the two species with negative values being for $N$. depressus and positive values being for C. mydas (Figure 1).

Average inter- and intra-assay coefficients of variation based on the absorbance of standards for $\mathrm{E}_{1}, \mathrm{~T}, \mathrm{DHT}, \mathrm{B}$, and $\mathrm{T}_{4}$ and the sensitivity for each assay are shown in Table 1.

Metabolites, blood glucose, and triglycerides are important sources of energy during responses to physiological and stress stimuli including nesting. No significant differences were observed in blood glucose and triglyceride concentrations between C. mydas and $N$. depressus (ANOVA: $\mathrm{F}_{1,32}=$ $2.23 ; 4.06 \pm 0.20$ versus $4.46 \pm 0.17 \mathrm{mmol} / \mathrm{L} ; \mathrm{F}_{1,32}=3.00$; $4.42 \pm 0.42$ versus $5.39 \pm 0.35 \mathrm{mmol} / \mathrm{L}, P>0.05)$.

3.2. Correlations among Hormones and Metabolites. In C. mydas, a positive correlation was observed between $\mathrm{T}$ and $\mathrm{P}$ (Pearson correlation: $r=0.8, P=0.0001$ ).

On the other hand in $N$. depressus, $\mathrm{T}$ was positively correlated with $\mathrm{P}(r=0.628, P=0.03)$ but also with $\mathrm{T}_{4}(r=$
0.512, $P=0.035)$. In addition, $\mathrm{B}$ was positively correlated with both $\mathrm{P}(r=0.473, P=0.03)$ and $\mathrm{E}_{1}(r=0.645$, $P=0.02)$.

3.3. Correlation of Nesting History, Carapace Length, Time of Oviposition, and Egg Size with Metabolites and Hormones in Natator depressus. We also analysed whether nesting history, carapace length, time of oviposition, and egg size might be correlated with the hormonal or metabolites plasma profile. Due to technical limitations we recorded measurements only for $N$. depressus. The results for this Pearson correlation analysis are given in Table 7. Significantly, negative correlations were observed between corticosterone and oestrone with time of oviposition $(r=-0.66$ and $r=-0.57, P<$ 0.01 , resp.), suggesting that the time of oviposition might influence corticosterone and oestrone levels in $N$. depressus. No statistically significant correlations were estimated for any other traits.

\section{Discussion}

Marine turtle species are globally distributed and hence exposed to varying environmental conditions. In this study, we observed the hormone and metabolite profiles of C. mydas and $N$. depressus. The reasons for the noted hormone and metabolite variations remain unknown. Critical information was missing on the nesting status (i.e., when a turtle was nested for the first time and the number of clutches laid in a nesting season) of the studied individuals at the time of sampling. In general, C. mydas nesting in Heron Island lays 5+ clutches [30] while $N$. depressus in Curtis Island lays approximately 3 clutches per season [31]. Knowing the 


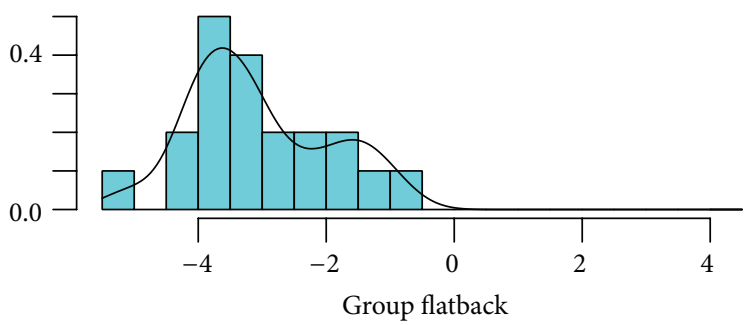

(a)

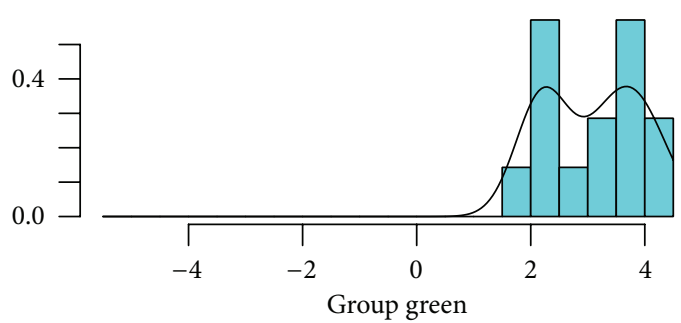

(b)

Figure 1: Histogram showing discriminant function scores for the Natator depressus $(\mathrm{a})(N=20)$ and Chelonia mydas (b) $(N=14)$ turtles. Negative scores for Natator depressus and positive scores for Chelonia mydas turtles.

TABle 6: Significance for Pearson correlation differences between Natator depressus $(N=20)$ and Chelonia mydas $(N=14)$. This table gives the $P$ value for the test $r 1=r 2$ where $r$ is the correlation for each "species" of turtles.

\begin{tabular}{|c|c|c|c|c|c|c|c|}
\hline & Progesterone & Testosterone & Corticosterone & Oestrone & DHT & Thyroxine & Triglycerides \\
\hline \multicolumn{8}{|l|}{ Progesterone } \\
\hline Testosterone & 0.35 & & & & & & \\
\hline Corticosterone & 0.53 & 0.94 & & & & & \\
\hline Oestrone & 0.84 & 0.31 & 0.08 & & & & \\
\hline DHT & 0.37 & 0.40 & 0.80 & 0.56 & & & \\
\hline Thyroxine & 0.09 & 0.05 & 0.35 & 0.18 & 0.66 & & \\
\hline Triglycerides & 0.44 & 0.52 & 0.53 & 0.63 & 0.15 & 0.20 & \\
\hline Glucose & 0.19 & 0.38 & 0.42 & 0.94 & 0.50 & 0.76 & 0.60 \\
\hline
\end{tabular}

deposited number of clutches is important because it could influence hormone levels in nesting turtles [6]. For example, hormones such as $\mathrm{P}, \mathrm{T}, \mathrm{E}_{2}$, and $\mathrm{B}$ are at higher levels at the beginning than at the end of a nesting season $[7,8,32]$. Nevertheless, C. mydas sampling occurred during a 3-month period; hence, it was highly unlikely that all of the individuals were at the same nesting status. In addition, hormone level variations as observed from the given SE within individuals of both species were minimum.

This study revealed a different hormone and metabolite profile for C. mydas and $N$. depressus. These discrepancies might have been influenced by diet and/or geographical location parameters. Chelonia mydas, as a herbivorous species, is predominantly feeding on sea grass, seaweeds, and algae [33] and, depending on the foraging site, its diet can vary, characterising this species as an opportunistic forager [34]. On the contrary, $N$. depressus is carnivorous and is feeding primarily on soft-bodied invertebrates, including jellyfish, sea cucumbers, sea pens, and soft corals [35]. Indeed, progesterone levels have been reported to be high (C. mydas and C. caretta [36]) or low (C. mydas and C. caretta [37] and Dermochelys coriacea [38]) or to decline after a clutch deposition (C. caretta [6] and Lepidochelys kempii [39]) in different nesting turtle populations worldwide. We observed that progesterone, as the major female sex steroid hormone during pregnancy, had the highest plasma concentration whereas DHT, a major testosterone derivative that is mainly observed in males, showed the lowest plasma concentration of the six analysed steroid hormones in both turtle species. In a previous study it has been shown that progesterone binds with low affinity and capacity in the plasma of nesting $C$. mydas [40], explaining the high progesterone levels found for C. mydas in this study.

In contrast to progesterone, both testosterone and oestradiol bind with high affinity and low capacity to sex steroid binding protein (SSBP), indicating that most of this hormone remains bound to a high affinity carrier in the body of nesting C. mydas [40]. Prior to migration to nesting sites, female turtles increase their T concentrations [32]. Whittier et al. [6] previously reported a correlation between testosterone and corticosterone in nesting $C$. caretta but such a correlation was not observed either in N. depressus or in C. mydas (C. mydas $[7,8]$; this study). All these observations together suggest a pivotal role of testosterone that is specific to each female turtle species enabling completion of nesting. In addition, the parallel analysis of steroid profiles in C. mydas and $N$. depressus in this study for the first time supports that steroid plasma hormone concentrations are species and possibly genetic populations specific and they might be influenced by various factors.

Nevertheless, the link between oestrone levels and time of oviposition in $N$. depressus also supports the hypothesis that hormone profiles, as well as their formed correlations with various factors (e.g., time of oviposition), are interactive for the successful nesting activities. We postulate that oestrone, together with oestradiol, might play an essential function during nesting in turtles. Despite the important role played by androgenic hormones, oestrogenic hormones 
TABLE 7: Pearson correlations between (a) turtle size, egg dimension, time of oviposition, (b) nesting history, and hormones/metabolites in Natator depressus.

(a)

\begin{tabular}{lccc}
\hline & Turtle size & $\begin{array}{c}\text { Egg } \\
\text { dimension }\end{array}$ & Decimal time \\
\hline Testosterone & $-0.22(0.36)$ & $-0.36(0.17)$ & $-0.02(0.94)$ \\
Corticosterone & $-0.19(0.42)$ & $-0.07(0.8)$ & $-0.66(0.00)$ \\
Oestrone & $-0.32(0.16)$ & $-0.27(0.32)$ & $-0.57(0.01)$ \\
DHT & $-0.1(0.69)$ & $-0.11(0.69)$ & $0.02(0.95)$ \\
Thyroxine & $-0.38(0.10)$ & $-0.24(0.37)$ & $-0.19(0.41)$ \\
Triglycerides & $0.18(0.45)$ & $0.47(0.06)$ & $-0.27(0.25)$ \\
Glucose & $-0.05(0.82)$ & $0.08(0.77)$ & $-0.16(0.51)$ \\
\hline
\end{tabular}

Note: $P$ values are given in brackets.

(b)

\begin{tabular}{lccc}
\hline & \multicolumn{2}{c}{ Time period } & $P$ value \\
& $<1997$ & $>1997$ & \\
\hline Glucose & $4.43(0.14)$ & $4.55(0.20)$ & 0.65 \\
Testosterone & $0.79(0.06)$ & $0.88(0.09)$ & 0.43 \\
Corticosterone & $0.44(0.08)$ & $0.38(0.11)$ & 0.66 \\
Estrone & $1.52(0.08)$ & $1.546(0.12)$ & 0.84 \\
DHT & $2.36(0.90)$ & $2.44(0.13)$ & 0.63 \\
Thyroxine & $0.37(0.33)$ & $0.42(0.05)$ & 0.37 \\
Triglycerides & $5.63(0.26)$ & $5.08(0.36)$ & 0.24 \\
\hline
\end{tabular}

are the most vital hormones during nesting in sea turtles. Previous studies have been focused predominantly on oestradiol measurements in nesting turtles. Oestradiol $17 \beta$ remains low or is at undetectable levels in nesting C. mydas and $C$. caretta turtles $[6-8,36]$. However, other researchers have previously suggested that there must be another major oestrogenic hormone besides oestradiol in nesting turtles (e.g., $[6,36])$. Indeed, oestrone plasma levels were higher than those of oestradiol in nesting C. mydas on Raine Island [23], supporting our conclusion about the major role of oestrone in nesting turtles. Nevertheless, we should emphasise that due to insufficient plasma quantity we were unable to measure oestradiol and verify whether its concentration was indeed lower than oestrone as hypothesised. Finally, the fact that $N$. depressus produces the largest eggs among turtle species [41] and that oestrone levels are influenced by the oviposition time in this species supports the need for further studies in a larger range of sea turtle species and populations that will provide conclusive insights into the role of this hormone in the aforementioned nesting parameters.

In respect to corticosterone levels, as found for the levels of oestrone, our data suggest that they were influenced by the oviposition time in $N$. depressus. Corticosterone levels were low in both nesting species. However, because corticosterone concentrations in C. mydas were below assay sensitivity levels, caution should be exercised when interpreting these results.
Having said this, the low corticosterone concentrations in $C$. mydas have been characterised as an adaptive mechanism for optimising the reproductive success during stressful situations $[9,10]$. Even at such low concentrations as these measured in this study, corticosterone may regulate and supply the necessary energy for the nesting cycle for C. mydas as it has previously been suggested $[7,8]$.

It should also be highlighted that in this study we identified the two turtle species $100 \%$ correctly, using discriminant analysis, based on three hormone levels (i.e., oestrone, progesterone, and testosterone). We suggest that during nesting these hormones are very distinguishable in C. mydas and $N$. depressus.

\section{Conclusions}

In conclusion, this study provides some fundamental baseline insights into the hormonal and metabolite patterns of two nesting turtle species with different diet preferences, geographical locations, and evolution pathways. We postulate that the hormone and metabolite differences as well as their interactions were meaningful and necessary for the successful completion of nesting activities, reflecting the species evolved physiological uniqueness and their complexity during nesting. We propose that oestrone is a major oestrogenic hormone in nesting turtles modulating, along with corticosterone at least in $N$. depressus, time of oviposition. Understanding the hormonal patterns of these species could lead us to comprehend better the effect of turtle species adaptation to different environments.

Finally, we were able to successfully distinguish nesting C. mydas and N. depressus based on the hormone profile of oestrone, progesterone, and testosterone, leading to potential new investigation pathways for identifying turtle species at particular life stages.

\section{Conflict of Interests}

The authors declare that there is no conflict of interests regarding the publication of this paper.

\section{Acknowledgments}

This work was supported by an Australian Research Council Linkage grant (LP0455513) to JMW and HO (Queensland Health Scientific Services; QHSS). All experiments were performed in accordance with approval by the Animal Ethics Committee of the University of Queensland (nos. ANAT/238/ 06/UQ-ARC/Earthwatch/URG and ANAT/352/07/UQARC/Earthwatch/URG) and the Queensland Environmental Protection Agency (QPWS permit numbers WISP03952406). The authors thank the Malaysian Fisheries Department Team, the rangers in K.T. They thank also the Environmental Protection Agency Team, the project staff, and the volunteers for the 2006 Curtis Island nesting census project. 


\section{References}

[1] M. Hau, R. E. Ricklefs, M. Wikelski, K. A. Lee, and J. D. Brawn, "Corticosterone, testosterone and life-history strategies of birds," Proceedings of the Royal Society B. Biological Sciences, vol. 277, no. 1697, pp. 3203-3212, 2010.

[2] E. J. Crespi, T. D. Williams, T. S. Jessop, and B. Delehanty, "Life history and the ecology of stress: how do glucocorticoid hormones influence life-history variation in animals?" Functional Ecology, vol. 27, no. 1, pp. 93-106, 2013.

[3] D. Crews, J. Sakata, and T. Rhen, "Developmental effects on intersexual and intrasexual variation in growth and reproduction in a lizard with temperature-dependent sex determination," Comparative Biochemistry and Physiology C: Pharmacology Toxicology and Endocrinology, vol. 119, no. 3, pp. 229-241, 1998.

[4] T. Wibbels, J. J. Bull, and D. Crews, "Chronology and morphology of temperature-dependent sex determination.," Journal of Experimental Zoology, vol. 260, no. 3, pp. 371-381, 1991.

[5] D. Crews, A. R. Cantú, T. Rhen, and R. Vohra, “The relative effectiveness of estrone, estradiol-17 $\beta$, and estriol in sex reversal in the red-eared slider (Trachemys scripta), a turtle with temperature-dependent sex determination," General and Comparative Endocrinology, vol. 102, no. 3, pp. 317-326, 1996.

[6] J. M. Whittier, F. Corrie, and C. Limpus, "Plasma steroid profiles in nesting loggerhead turtles (Caretta caretta) in Queensland, Australia: relationship to nesting episode and season," General and Comparative Endocrinology, vol. 106, no. 1, pp. 39-47, 1997.

[7] M. Hamann, T. S. Jessop, C. J. Limpus, and J. M. Whittier, "Interactions among endocrinology, seasonal reproductive cycles and the nesting biology of the female green sea turtle," Marine Biology, vol. 140, no. 4, pp. 823-830, 2002.

[8] M. Hamann, C. J. Limpus, and J. M. Whittier, "Patterns of lipid storage and mobilisation in the female green sea turtle (Chelonia mydas)," Journal of Comparative Physiology B, vol. 172, no. 6, pp. 485-493, 2002.

[9] T. S. Jessop, N. N. FitzSimmons, C. J. Limpus, and J. M. Whittier, "Interactions between behavior and plasma steroids within the scramble mating system of the promiscuous green turtle, Chelonia mydas," Hormones and Behavior, vol. 36, no. 2, pp. 8697, 1999.

[10] T. S. Jessop, C. J. Limpus, and J. M. Whittier, "Plasma steroid interactions during high-density green turtle nesting and associated disturbance," General and Comparative Endocrinology, vol. 115, no. 1, pp. 90-100, 1999.

[11] T. S. Jessop, "Modulation of the adrenocortical stress response in marine turtles (Cheloniidae): evidence for a hormonal tactic maximizing maternal reproductive investment," Journal of Zoology, vol. 254, no. 1, pp. 57-65, 2001.

[12] R. A. Valverde, D. W. Owens, D. S. MacKenzie, and S. M. Amoss Jr., "Basal and stress-induced corticosterone levels in olive Ridley sea turtles (Lepidochelys olivacea) in relation to their mass nesting behavior," Journal of Experimental Zoology, vol. 284, pp. 652-662, 1999.

[13] T. S. Jessop and M. Hamann, "Hormonal and metabolic responses to nesting activities in the green turtle, Chelonia mydas," Journal of Experimental Marine Biology and Ecology, vol. 308, no. 2, pp. 253-267, 2004.

[14] S. Wright, Samson Wright's Applied Physiology, Oxford University Press, Oxford, UK, 1984.

[15] K. A. Bjorndal, "Nutritional ecology of sea turtles," Copeia, pp. 736-751, 1985.
[16] A. D. Tucker and M. A. Read, "Frequency of foraging by gravid green turtles (Chelonia mydas) at Raine Island, Great Barrier Reef," Journal of Herpetology, vol. 35, no. 3, pp. 500-503, 2001.

[17] K. Schmidt-Nielsen, "Energy metabolism," in Animal Physiology, Adaptation and Environment, K. Schmidt-Nielsen, Ed., p. 612, Cambridge University Press, Cambridge, Mass, USA, 2004.

[18] J. F. Leatherland, "Thyroid response to ovine thyrotropin challenge in cortisol- and dexamethasone-treated rainbow trout, Salmo gairdneri," Comparative Biochemistry and Physiology A, vol. 86, no. 2, pp. 383-387, 1987.

[19] C. J. Limpus, "The flatback turtle, Chelonia depressa Garman in southeast Queensland, Australia," Herpetologica, vol. 27, pp. 431-446, 1971.

[20] C. J. Limpus, C. J. Parmenter, R. Parker, and N. Ford, "The flatback turtle Chelonia depressa in Queensland the Peak Island rookery," Herpetofauna, vol. 13, pp. 14-18, 1981.

[21] D. W. Owens and G. J. Ruiz, "New methods of obtaining blood and cerebrospinal fluid from marine turtles," Herpetologica, vol. 36, pp. 17-20, 1980.

[22] A. B. Bolten, "Techniques for measuring sea turtles," in Research and Management Techniques for the Conservation of Sea Turtles, K. L. Eckert, K. A. Bjorndal, F. A. Abreu-Grobois, and M. Donnelly, Eds., pp. 110-114, UCN/SSC: Marine Turtle Specialist Group, 1999.

[23] K. Coufal and J. M. Whittier, "Identification of oestrone as a major oestrogenic steroid in marine turtle plasma as detected by HPLC. Short Communication," in Proceedings of the 22nd Annual Symposium on Sea Turtle Biology and Conservation, J. A. Seminoff, Ed., NOAA Technical Memorandum NMFS-SEFSC 503, pp. 200-201, 2003.

[24] C. E. Franklin, B. M. Davis, S. K. J. Peucker et al., "Comparison of stress induced by manual restraint and immobilisation in the estuarine crocodile, Crocodylus porosus," Journal of Experimental Zoology A: Comparative Experimental Biology, vol. 298, no. 2, pp. 86-92, 2003.

[25] M. P. Ikonomopoulou, Steroid hormones, steroid binding proteins and persistent environmental pollutants in green (Chelonia mydas) and flatback (Natator depressus) turtles [Ph.D. thesis], The University of Queensland, St Lucia, Australia, 2008.

[26] R Core Team, R: A Language and Environment for Statistical Computing, R Foundation for Statistical Computing, Vienna, Austria, 2013, http://www.R-project.org/.

[27] R. V. Lenth, "lsmeans: Least-squares means," R package version 1.10-14, 2013, http://CRAN.R-project.org/package=lsmeans.

[28] F. E. Harrell Jr., C. Dupont et al., Hmisc: Harrell Miscellaneous, R Package Version 3.12-2, 2013, http://cran.r-project.org/web/ packages/Hmisc/index.html.

[29] W. N. Venables and B. D. Ripley, Modern Applied Statistics, Springer, New York, NY, USA, 2002.

[30] C. J. Limpus, A Biological Review of Australian Marine Turtles, Queensland Government Environment Protection Agency, Brisbane, Australia, 2009.

[31] C. J. Limpus, Conservation of Marine Turtles in the Indo-Pacific Region, Queensland Department of Environment and Heritage, Brisbane, Australia, 1995.

[32] T. Wibbels, D. W. Owens, C. J. Limpus, P. C. Reed, and M. S. Amoss Jr., "Seasonal changes in serum gonadal steroids associated with migration, mating, and nesting in the loggerhead sea turtle (Caretta caretta)," General and Comparative Endocrinology, vol. 79, no. 1, pp. 154-164, 1990. 
[33] D. Gulko and K. Eckert, Eds., Sea Turtles: An Ecological Guide, Mutual Publishing, Honolulu, Hawaii, USA, 2004.

[34] K. E. Arthur, Ecotoxicology of the cyanobacterium Lyngbya majuscula and health implications for green sea turtles (Chelonia mydas) [Ph.D. Thesis], The University of Queensland, Queensland, Australia, 2005.

[35] C. J. Limpus, "A biological review of Australian marine turtle species, 5 Flatback turtle, Natator depressus (Garman)," Environmental Protection Agency, Brisbane, Australia, 2007.

[36] T. Wibbels, D. W. Owens, P. Licht, C. Limpus, P. C. Reed, and M. S. Amoss Jr., "Serum gonadotropins and gonadal steroids associated with ovulation and egg production in sea turtles," General and Comparative Endocrinology, vol. 87, no. 1, pp. 7178, 1992.

[37] P. Licht, W. Rainey, and K. Cliffton, "Serum gonadotropin and steroids associated with breeding activities in the green sea turtle, Chelonia mydas. II. Mating and nesting in natural populations," General and Comparative Endocrinology, vol. 40, no. 1, pp. 116-122, 1980.

[38] D. C. Rostal, J. S. Grumbles, K. S. Palmer, V. A. Lance, J. R. Spotila, and F. V. Paladino, "Changes in gonadal and adrenal steroid levels in the leatherback sea turtle (Dermochelys coriacea) during the nesting cycle," General and Comparative Endocrinology, vol. 122, no. 2, pp. 139-147, 2001.

[39] D. C. Rostal, D. W. Owens, J. S. Grumbles, D. S. MacKenzie, and M. S. Amoss Jr., "Seasonal reproductive cycle of the Kemp's ridley sea turtle (Lepidochelys kempi)," General and Comparative Endocrinology, vol. 109, no. 2, pp. 232-243, 1998.

[40] M. P. Ikonomopoulou, A. J. Bradley, J. M. Whittier, and K. Ibrahim, "Identification and properties of steroid-binding proteins in nesting Chelonia mydas plasma," Journal of Comparative Physiology B, vol. 176, no. 8, pp. 775-782, 2006.

[41] J. R. Spotila, Sea Turtles: A Complete Guide to their Biology, Behavior, and Conservation, Johns Hopkins University Press, Baltimore, Md, USA, 1994. 

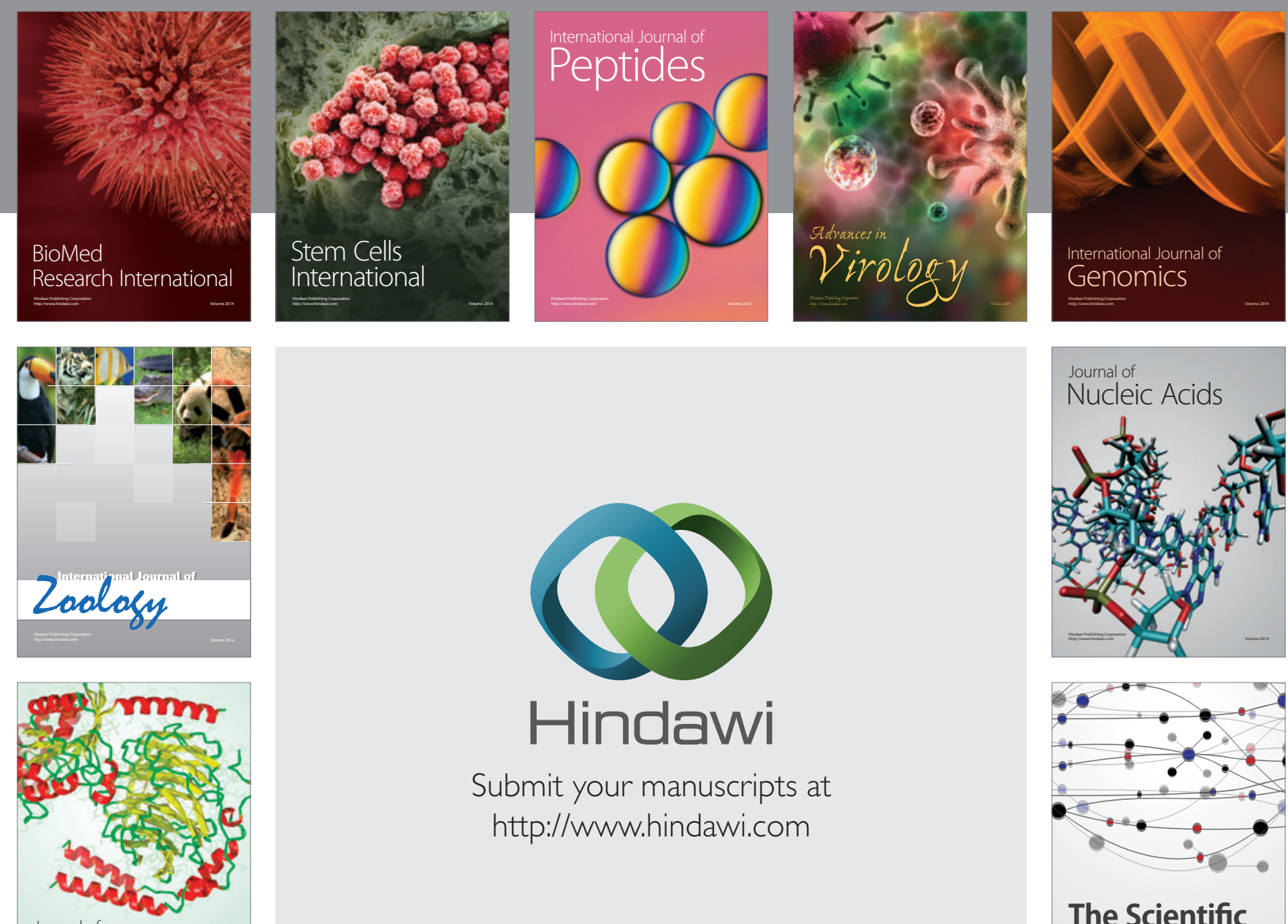

Submit your manuscripts at

http://www.hindawi.com

Journal of
Signal Transduction
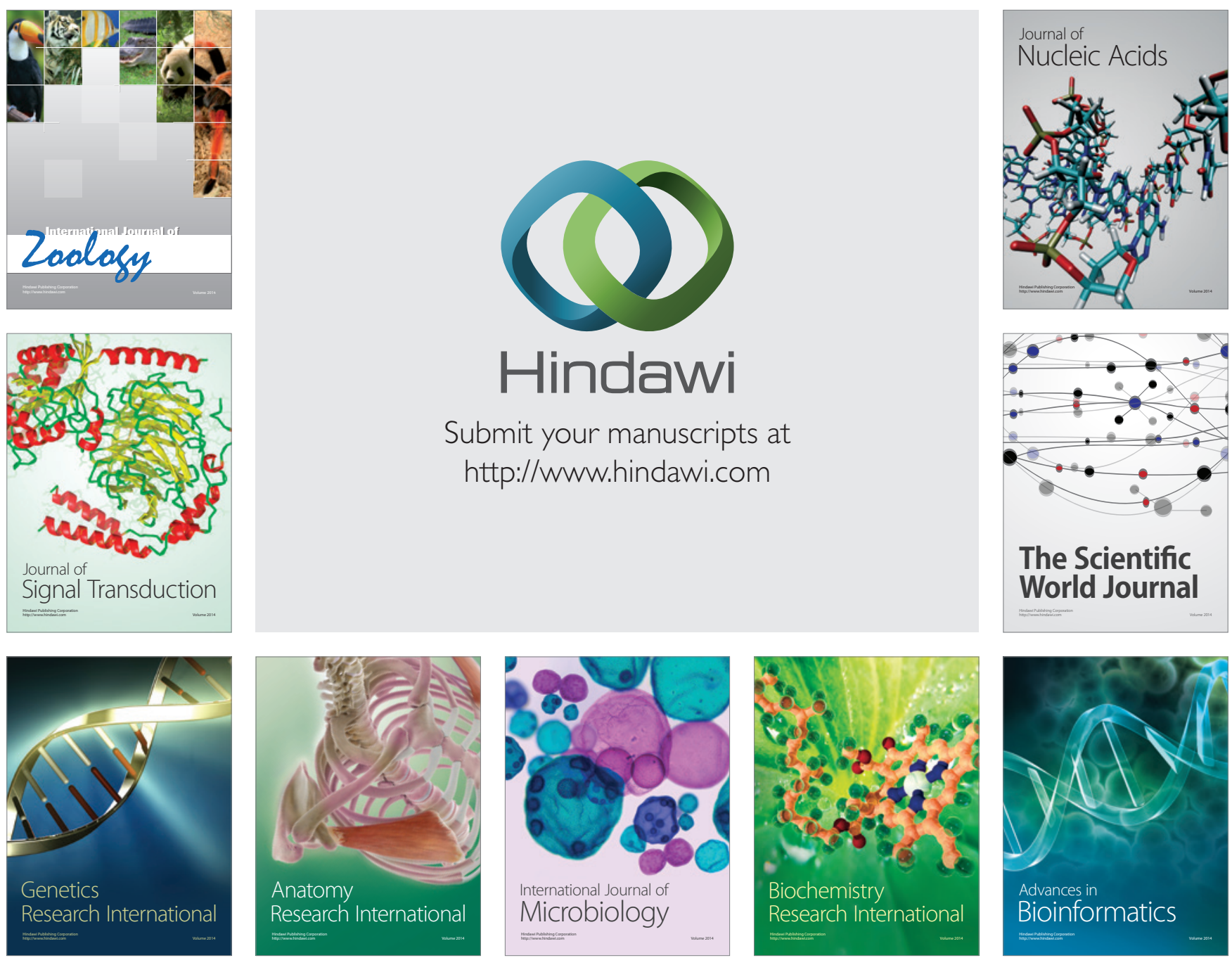

The Scientific World Journal
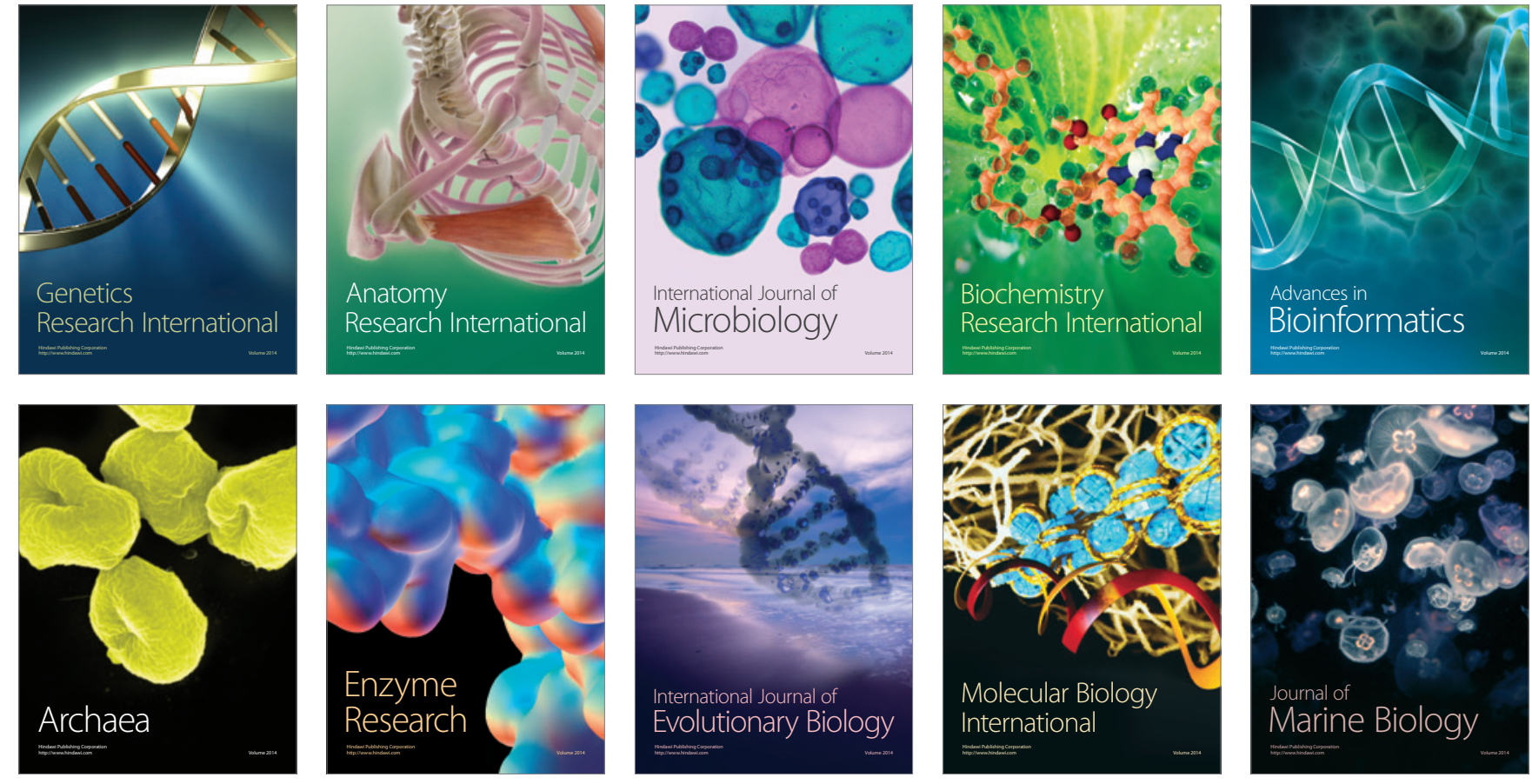